\title{
Design and Fabrication of Hybrid Two Wheeler
}

\author{
Inzamam Ul Haq Rizvi \\ $\mathrm{BE}$ in automobile \\ BMCET, SURAT \\ Smit Shah \\ BE in automobile \\ BMCET, SURAT
}

\author{
Manav Matliwala \\ BE in automobile \\ BMCET, SURAT \\ Pappu Yadav \\ BE in automobile \\ BMCET, SURAT
}

\author{
Mr. Jignesh Soni \\ Asst professor \\ BMCET, SURAT
}

\begin{abstract}
As we all know that as the population is increasing day by day the vehicle users are also increasing and the number of vehicles are also increasing day by day. As we all know very well that vehicles run on petrol diesel CNG and LPG. This all fuels are the by-product of fossil fuel. As the number of vehicles increasing the use of fossil fuels are also increasing due to there the shortage of this fuel are seen in market and due to that the cost of that fuel is also increasing. Another disadvantage is that that after combustions of this fuel harmful gases are produce which cause air pollution. So we are going to introduce a hybrid two wheeler vehicle which will work on both fuel and electric power. In this we are going to attach motor directly with the gear box.
\end{abstract}

\section{INTRODUCTION}

Hybrids have become a necessity in the current world automotive scenario. Fossil fuels have served as the primary source of power for automobiles over the years. The constant reminder that the fossil fuels are diminishing at an unprecedented rate has posed a challenge to the automotive future. Although electric vehicles may seem like the solution to the problem of depleting fossil fuels, the various issues with the implementation of electric systems restricts it from being so. The sheer cost of the vehicles and establishment of refueling stations have rendered the use of electric vehicles a concept than reality. Hybrids are relatively much easier to implement as they are more of a modification to the existing combustion system than an entirely new concept. Hybrids have been successfully implemented in four wheelers for over a decade now. The two-wheeler scenario is on the other hand, facing a lot of problems trying to cope with the percentage of increase in the cost of implementing a hybrid. The cost of implementing hybrids into two wheelers is much lower than in four wheelers but the percentage increase in the market value of a vehicle is higher in two wheelers, which leads the customers to believe that the two-wheeler hybrids are unreasonably priced.

\section{A PARALLEL HYBRID EV}

In parallel hybrids, both IC engine and motor are directly connected to the drive system so that they can individually (during low traction power demand) or jointly (during high power demand) propel the vehicle. Most PHEV designs combine the generator and motor into one unit. In parallel drive mode, the supplied torques is added together. When only one of the two drives is in service, the other will be disconnected through a clutch. PHEVs are relatively more compact as they use a smaller battery pack than other hybrids and needs a smaller traction motor. The drawback of PHEV is the need for complex mechanical systems and control algorithms.

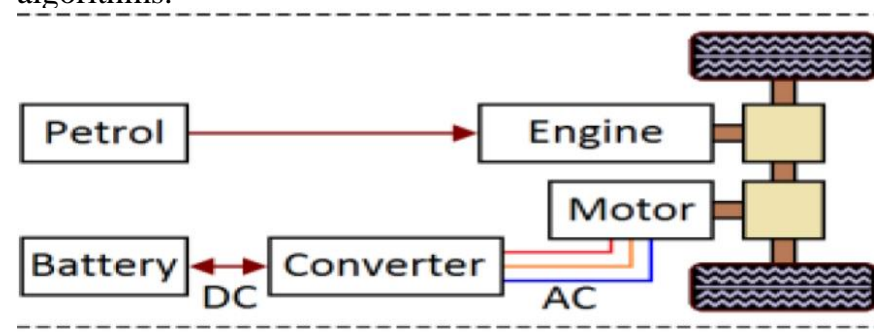

\section{B SERIES HYBRID EV}

Series drive train is the simplest hybrid configuration. In this design, the electric motor alone delivers the vehicle traction power as the engine is not connected to the drive train. The traction motor is powered by a battery or by an electric generator driven by the downsized IC engine. The generator powers the drive motor when the traction load demand is large or charges the batteries when the motor load demand is small. The motor can also operate as generator during braking and coasting. Series hybrids are the most efficient in driving cycles that require frequent stops and starts such as for delivery vehicles, urban buses and stop and go city driving. The drawbacks of SHEV: (i) needs separate generator and motor sections (which means increased cost and reduced efficiency due to more systems), (ii) needs large size drive motor rated for maximum power needs such as climbing uphill. However, since series hybrids use a bigger electric machine in the propulsion system, their energy recovery capability is much higher than other HEVs. Example: Nissan e-Power. 


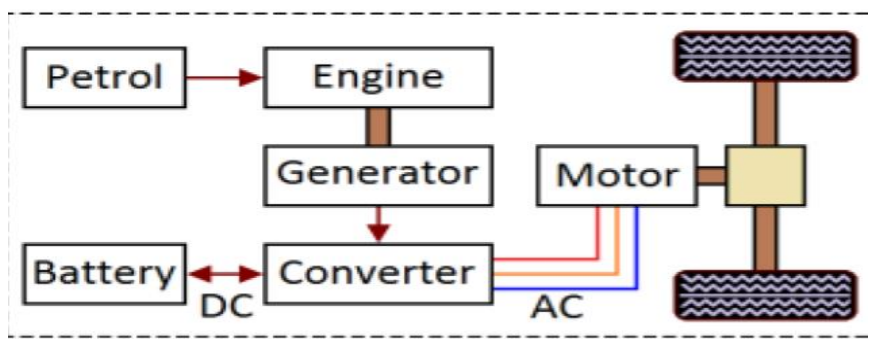

\section{SERIES PERALLEL HYBRIDE EV}

Series-parallel hybrids (or power-split hybrids) combine the benefits of both series and parallel architecture. The powersplit device divides the output from the engine into mechanical and electrical transmission paths. This design is capable of providing continuous high output power as compared to series or parallel powertrain. They use smaller motors. Series-parallel hybrids can achieve similar operating modes as series hybrid vehicles. However, it requires very complex control system.

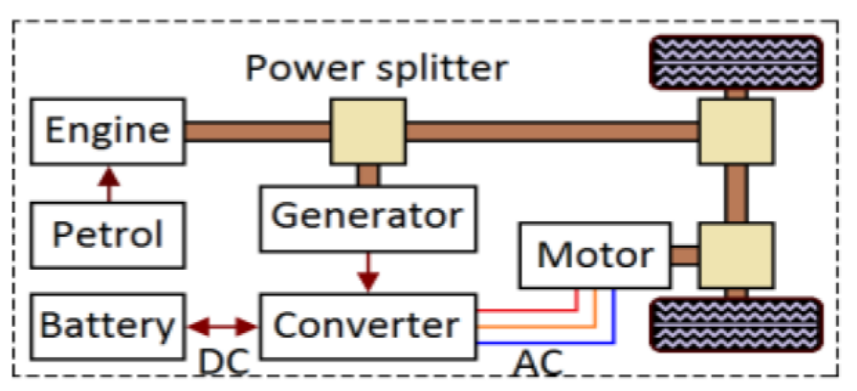

\section{LITRETURE REVIEW}

SHARADA PRASAD, Dr. K. R. NATARAJ [1] studied The hybrid electric vehicle consists of two or more energy sources for total propulsion of the vehicle. The ICE in this built hybrid electric vehicle is utilized for obtaining the propulsion of the vehicle from the rest, as the speed is increased; the electric motor propulsion is combined with the ICE propulsion for total movement of the vehicle. For the test route chosen, the vehicle in stock condition, eligible for giving a mileage of $35 \mathrm{~km}$, With this type of arrangement, can enhance the mileage performance efficiently by $25 \%$.

Ruthvik P [2] studied a petrol engine which drives the rear wheel and a battery connected to a motor which drives the front wheel. At low speeds, the motor is highly efficient and the engine's efficiency is low besides emitting a lot of hazardous substances and creating noise pollution while idling and in slow moving traffics. As the speed increases, the motor becomes inefficient and the engine's efficiency increases, hence the engine takes over at the higher speeds. Thus it is most efficient in urban areas mainly in high traffic where petrol engines are least efficient, reducing emission and fuel consumption which is high at low speeds.

Shaik Amjad, R. Rudramoorthy [3] studied the impact of an actual drive pattern on the sizing and cost of a battery pack for a plug-in hybrid electric two-wheeler. A study conducted in Coimbatore city is helpful in estimating the daily average travel distance and also to develop the real-world driving pattern. The real-world driving pattern has shown a higher peak power demand of $29 \%$ and $17-19 \%$ of more energy than the IDC based on battery type. Based on the analysis, it is noted that $\mathrm{Ni}-\mathrm{MH}$ batteries are more economical and suitable for implementing in plug-in hybrid electric two-wheelers.

Vijay B, Shanmughasundaram $R$ [4] studied the performance of an HEV relies on the effective usage of the two power source (ICE and electric motor). The aim is to develop a control strategy to optimize the torque split between the power sources. PTTR hybrid vehicle is modeled with MATLAB to analyze the power flow across the components. Simulation results show that the fuel consumption is lesser in case of adaptive fuzzy logic. The proposed method could be implemented on a microcontroller and can be used as Vehicle Control Unit (VCU). As a future scope, the response time can be made quicker by making use of parallel computing.

N.Boopalan, Marlon Jones Louis, A.K.Nachimuthu [5] studied the hybrid electric vehicle model combines the internal combustion engine of a conventional vehicle with the battery and electric motor of an electric vehicle, resulting in twice the fuel economy of conventional vehicle. In heavy traffic and inside the city there is no chance for moving fast. At that time, if vehicle is run by IC engine, more fuel is wasted due to variation of acceleration. During less load operation, vehicle can be easily run by mean of battery instead of by engine, when high torque is required it can be changed to IC engine mode.

Harish N, Amar Thakur, [6] studied The power train efficiency of the range-extended electric vehicle is compared in different driving cycles, energy management strategies, and range-extended control methods the range-extender uses thermostat control method, the system efficiency is the maximum. The energy efficiency can reach 33\%, the comprehensive efficiency of the generator, rectifier can reach above $90 \%$. Compared to ordinary bikes this hybrid bike is more efficient and economic. This hybrid bike will be an innovation in automotive era, it is more eco-friendly because it cause less pollution.

Mr. Aniket Badgujar, Prof. S. S. Surve, Mr. Yadnesh Keny [7] studied hybrid electric vehicles combine an electric motor, battery and power system and with an internal combustion engine to achieve charging capacity for battery due to which better fuel economy and reduce toxic emissions. In HEVTWD, the battery alone provides power for low-speed driving conditions where internal combustion engines are used for charging the battery. The mileage of the bike is increased from 60 to $90 \mathrm{~km}$ for 1 liters of gasoline and fully charger battery.

\section{SUMMARY OF LITRETURE}

We conclude from above literature that mostly all literature have similar disadvantages that the speed of vehicle is very low. The efficiency of the vehicle is also low so it can use only for city driving. The pickups of the vehicle are the major problem in all papers. In this project we are going to overcome all the limitation of the electric vehicle and try to get high efficiency. 


\section{WORKING METHOD}

In this project we are going to use both the energy electric motor and I.C engine in a single run. As we have mention above the different type of hybrid vehicle we are going to use parallel hybrid method in our project. As we know the vehicle need maximum torque at the initial stage to bring the vehicle in motion. After that the vehicle only needs high rpm and less torque to maintain the speed and to increase the speed of the vehicle. The initial torque is the biggest barrier for electric vehicle and due to this there is decrement in the efficiency of the vehicle.

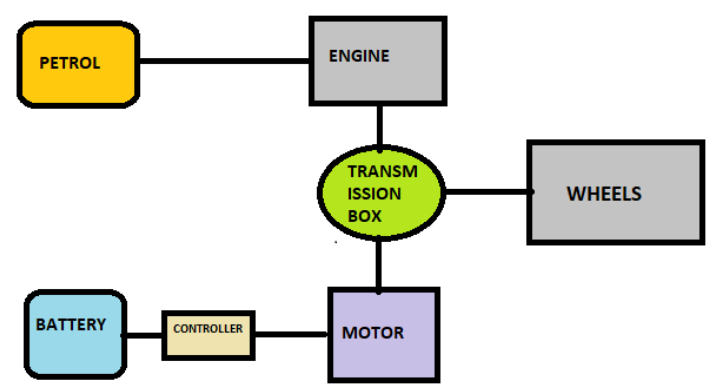

To overcome this limitation we are going to use this method in some different way. In our project we have given the electric power in the gear box instead of giving directly in the wheels. We are going to transfer motor rotation through a chain drive in the input shaft of the gear.

When we start the vehicle and run it at $1^{\text {st }}$ gear we will give power through I.C engine which required high torque. We will continue the run up to last second gear through I.C engine only. Now when we bring our vehicle at final gear we will keep the clutch in disengaged position and instead of giving throttle to engine we will transfer the rotation through electric motor. As in final gear vehicle only needs rpm and less torque to maintain and to increase the speed this need can be fulfill by electric motor in this vehicle. In this way this project will work.

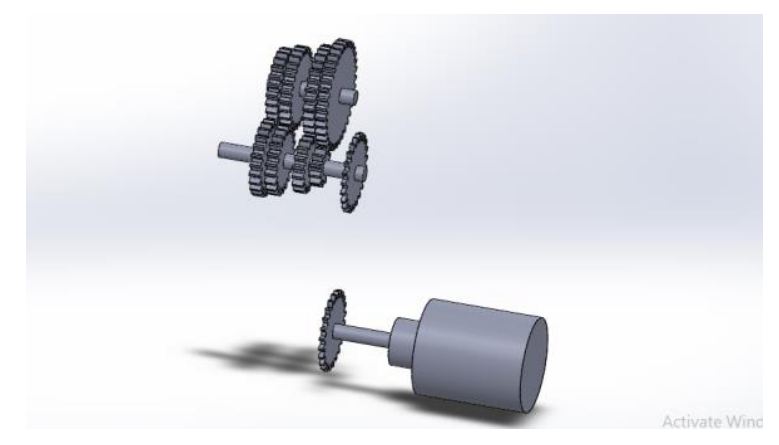

\section{COMPONENTS}

The components which we used in this project are

1. We have fabricated a new input shaft by increasing its length and attaching a sprocket gear over it.

2. Motor: we have used dc motor of 1000 watt which work on 36 volt battery which give rotation to output shaft of $3000 \mathrm{rpm}$

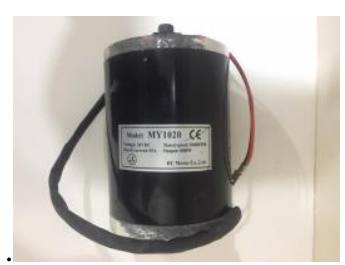

3. Controller: it controls the amount of current which is transfer from the battery to the motor.

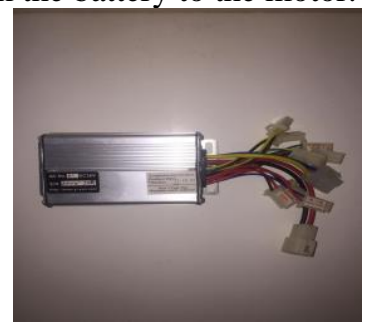

4. Resistor: it works as a throttle substance for the motor from it we can control the speed of the vehicle.

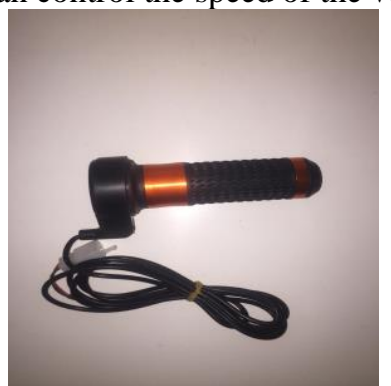

5. Bike: we have assembled all the component in this bike

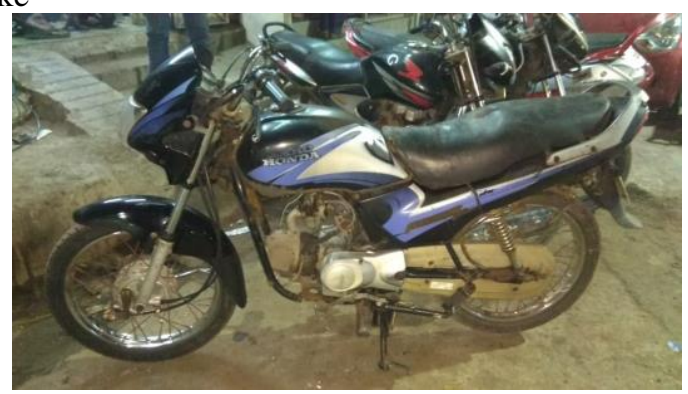

\section{CONCLUSION}

We conclude that by this method we will get high efficiency in the vehicle and can get high speeds which are the biggest limitation of the hybrid vehicles. We can also control the amount of harmful gases produced. By using this method we can further advance the vehicle and make it more efficient and effective.

\section{REFERENCES}

[1] SHARADA PRASAD, Dr. K. R. NATARAJ "DESIGN AND DEVELOPMENT OF HYBRID ELECTRIC TWOWHEELER WITH SOLAR CHARGING METHODOLOGY" International Journal of Scientific \& Engineering Research, Volume 5, Issue 11, November2014

[2] Ruthvik P. Sankar, Sagar N, Sarthak J, Shubham P. Toraskar, Yashvanth Kumar "Design and Development of Smart Hybrid Two Wheeler" International Journal of Innovative Research in Science, Engineering and Technology Vol. 6, Issue 6, June 2017

[3] Shaik Amjad, R. Rudramoorthy, S. Neelakrishnan, K. Sri Raja Varman, T.V. Arjunan "Impact of real world driving pattern and all-electric 
range on battery sizing and cost of plug-in hybrid electric two-wheeler" Journal of Power Sources 196 (2011) 3371-3377

[4] Vijay B, Shanmughasundaram R "Control Strategy for Parallel Hybrid Electric Vehicles” Procedia Computer Science 143 (2018) 678-685

[5] N.Boopalan, Marlon Jones Louis 2, A.K.Nachimuthu "DESIGN AND FABIRCATION OF HYBRID TWO WHEELER" International Journal of Research and Innovation in Engineering Technology Volume: 01 Issue: 01

[6] Harish N, Amar Thakur, Alwin George, Mahmadali Babu Sab Nadel "Hybrid Two-Wheeler" International Journal of Latest Engineering
Research and Applications Volume - 03, Issue - 05, May 2018, PP 45-47

[7] Mr. Aniket Badgujar, Prof. S. S. Surve, Mr. Yadnesh Keny, Mr Gaurang Kadam "Hybrid Two Wheel Drive Motorcycle with Range Extender" International Journal for Scientific Research \& Development| Vol. 4, Issue 03, 2016 